\title{
Algunas reflexiones sobre el rol del Estado en la provisión de políticas públicas que se orien- tan al desarrollo sostenible ${ }^{(1)}$
}

\author{
Agustina Belén Huespe \\ Estudiante de Licenciatura en Economía. \\ Facultad de Ciencias Económicas - \\ Universidad Nacional del Litoral (UNL) \\ Email: aguhuespe16@gmail.com
}

Quizás al hablar un poco relativamente de lo complejo, queda la concepción de que todo debe ser complejizado. Es justo el trámite inverso, tener un pensamiento complejo es el más expeditivo camino para lograr conclusiones simples y claras, que nos acerquen a la certeza y nos alejen de la permanente incertidumbre de la ciencia y de la vida.

Edgar Morín

Fecha de recepción

$14 / 08 / 2014$

Fecha de aprobación $21 / 10 / 2014$

Palabras claves

- Estado

- políticas públicas

- participación ciudadana

- desarrollo sostenible

- instituciones

\section{Resumen}

El presente trabajo analiza el papel del Estado en la formulación de políticas públicas, en un entorno cada vez más preocupado por cuestiones ambientales, sociales y económicas. Estos aspectos configuran los pilares sobre los que se apoya el concepto de desarrollo sostenible. De este modo, a través de un recorrido sobre las distintas épocas, se analizan las reformas estatales y su consecuente relevancia. A su vez, se pone énfasis en la actuación de la sociedad y su intervención para medir la efectividad de dichas políticas públicas. 


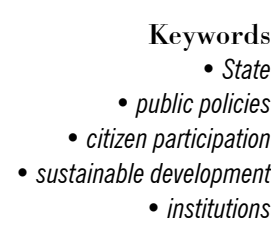

Keywords

- State measure the effectiveness of these public policies.

\section{Introducción}

A lo largo del tiempo, el desarrollo en términos económicos de los países del mundo se fue dando de una manera heterogénea. El ritmo de crecimiento no fue el mismo en las diversas regiones; así como tampoco lo fue en las distintas etapas de la época capitalista. Siguiendo a Madison (2004) se pueden diferenciar cinco fases en el progreso internacional. El período que va desde 1950 a 1973 se caracteriza por un gran incremento del Producto Bruto Interno (PBI) mundial y se denomina la «Edad de Oro». A partir de dicho año y hasta nuestros días, se abre una segunda mejor etapa llamada «orden neo-liberal». El viejo «orden liberal» es el tercer período en términos de prosperidad económica y abarca desde 1870 a 1913. La cuarta fase se dio a partir de la primera guerra mundial y hasta 1950 . Finalmente, la fase inicial del desarrollo capitalista (1820-1870) fue la que presentó un ritmo de crecimiento más lento.

Conforme se iban desarrollando las etapas, el papel del Estado iba tomando cada vez más relevancia 0 tornándose menos necesario según considere la doctrina de turno. Con las teorías del desarrollo de las décadas del 50 y 60, este organismo adquiere una gran trascendencia: su principal objetivo era acelerar la urbanización y modernizar la agricultura (Evans, 1992). Llegado el año 1970, el rumbo del Estado cambia. Se da el agotamiento del modelo hasta entonces vigente y la crisis de esta institución que desencadena la crítica a su rol de interventor en la economía (Lechner, 1992). Hacia la década del 80, se da un esfuerzo de toda la sociedad en su conjunto por «reintroducir al Estado» (Evans, citado en Smith, 1997); para acercarnos a los '90 con su total desmantelamiento y pérdida de funciones esenciales. Se inicia así en nuestro país, una verdadera «Reforma del Estado» que conlleva a la flexibilización en el mercado laboral, la desregulación y apertura del merado mundial y a asumir las políticas privatizadoras como fundamentales en las agendas estatales (Thwaites Rey, 1999). De este modo, se iba dando progresivamente la retirada del Estado de la economía y su consecuente reemplazo por manos de empresarios. Privatizaciones que, si bien en un primer momento contaron con el aval de la sociedad (cansada de las defectuosas prestaciones de los servicios públicos), en su ulterior desarrollo se llevaron a cabo sin mecanismos de consulta 0 de participación ciudadana (Azpiazu y Basualdo, 2004).

Entrando en el siglo XXI, se plantea otra perspectiva. Fenómenos como la globalización y el avance del capitalismo llevan a un cambio de enfoque. La contaminación, tanto del aire, como del suelo y agua, la deforestación, el cambio climático, los desastres naturales, el uso ilimitado de recursos; son una preocupación progresiva en material ambiental. A su vez, la pobreza, los bajos niveles de alfabetización, el deterioro en la calidad de prestación de servicios de salud, así como la creciente inseguridad; ocu- 